\title{
ASO Visual Abstract: Prognostic Impact of Resection Margin Status in Distal Pancreatectomy for Ductal Adenocarcinoma
}

\begin{abstract}
Mushegh A. Sahakyan, MD, PhD ${ }^{1,2,3}$ (D) , Caroline S. Verbeke, MD, $\mathrm{PhD}^{4,5}$, Tore Tholfsen, $\mathrm{MD}^{6}$, Dejan Ignjatovic, $\mathrm{MD}, \mathrm{PhD}^{4,7}$, Dyre Kleive, $\mathrm{MD}, \mathrm{PhD}^{6}$, Trond Buanes, $\mathrm{MD}, \mathrm{PhD}^{4}$, Kristoffer Lassen, $\mathrm{MD}, \mathrm{PhD}^{6,8}$, Bård I. Røsok, $\mathrm{MD}, \mathrm{PhD}^{6}$, Knut Jørgen Labori, $\mathrm{MD}, \mathrm{PhD}^{4,6}$, and Bjørn Edwin, $\mathrm{MD}, \mathrm{PhD}^{1,4,6}$

${ }^{1}$ The Intervention Centre, Rikshospitalet, Oslo University Hospital, Oslo, Norway; ${ }^{2}$ Division of Emergencies and Critical Care, Department of Research and Development, Oslo University Hospital, Oslo, Norway; ${ }^{3}$ Department of Surgery N1, Yerevan State Medical University, Yerevan, Armenia; ${ }^{4}$ Institute of Clinical Medicine, University of Oslo, Oslo, Norway; ${ }^{5}$ Department of Pathology, Rikshospitalet, Oslo University Hospital, Oslo, Norway; ${ }^{6}$ Department of Hepato-PancreatoBiliary Surgery, Rikshospitalet, Oslo University Hospital, Oslo, Norway; ${ }^{7}$ Department of Digestive Surgery, Akershus University Hospital, Lørenskog, Norway; ${ }^{8}$ Institute of Clinical Medicine, University of Troms $\emptyset$, Tromsö, Norway
\end{abstract}

Our study examines the resection margin status in distal pancreatectomy specimens with ductal adenocarcinoma focusing on pathology work-up (https://doi.org/10.1245/s 10434-021-10464-6). A meticulous, standardized procedure for specimen grossing is the key. Its systematic use shows that microscopic margin involvement occurs in most cases.

Supplementary Information The online version contains supplementary material available at https://doi.org/10.1245/s10434021-10531-y.
DISCLOSURE Mushegh A. Sahakyan, Caroline S. Verbeke, Tore Tholfsen, Dejan Ignjatovic, Dyre Kleive, Trond Buanes, Kristoffer Lassen, Bård I. Røsok, Knut Jørgen Labori, and Bjørn Edwin have no commercial interests or sources of financial or material support to declare.

Publisher's Note Springer Nature remains neutral with regard to jurisdictional claims in published maps and institutional affiliations.

Mushegh A. Sahakyan and Caroline S. Verbeke share first authorship on this work.

(C) Society of Surgical Oncology 2021

Published Online: 3 August 2021

M. A. Sahakyan, MD, $\mathrm{PhD}$

e-mail: sahakyan.mushegh@gmail.com 